\title{
NUMERICAL SIMULATION OF MOVING LOAD ON CONCRETE PAVEMENTS
}

\author{
Gabriela Lajčáková ${ }^{1}$, Jozef Melcer ${ }^{2}$ \\ ${ }^{1,2}$ University of Žilina, Faculty of Civil Engineering \\ Univerzitná 8215/1, 01026 Žilina, Slovak Republic \\ ${ }^{1}$ Phone: +421-41-513 5649, e-mail: gabriela.lajcakova@fstav.uniza.sk \\ 2Phone:+421-41-513 5649,e-mail:jozef.melcer@fstav.uniza.sk
}

\begin{abstract}
The knowledge of the development with time of the strain and stress states in pavement structures is needed in the solution of various engineering tasks as the design fatigue lifetime reliability maintenance and structure development. The space computing model of the truck TATRA 815 is introduced. The pavement computing model is created in the sense of Kirchhof theory of the thin slab on elastic foundation. The goal of the calculation is to obtain the vertical deflection in the middle of the slab and the time courses of vertical tire forces. The equations of motion are derived in the form of differential equations. The assumption about the shape of the slab deflection area is adopted. The equations of the motion are solved numerically in the environment of program system MATLAB. The dependences following the influence of various parameters (speed of vehicle motion, stiffness of subgrade, slab thickness, road profile) on the pavement vertical deflections and the vertical tire forces are introduced. The results obtained from the plate computing model are compared with the results obtained by the FEM analysis. The outputs of the numerical solution in the time domain can be transformed into a frequency domain and subsequently used to solve various engineering tasks.
\end{abstract}

Keywords: numerical simulation, moving load, computing models, concrete pavements, dynamic, tire forces

\section{Introduction}

The knowledge of the development with time of the strain and stress states in pavement structures is needed in solving various engineering tasks as the design fatigue lifetime reliability maintenance and structure development. The most effective solution of the problem of the vehicle - road interaction is the combination of numerical and experimental methods. The analysis can be performed in the time or in the frequency domain. Numerical analysis demands to pay attention to these separated problems: vehicle computing models, pavement computing models, road profile, solutions of equations of motion, programming, processing and interpretation of obtained results. The finite element method is commonly used. But there are also other possibilities of the solution. In this contribution the computing model of the concrete pavement based on the theory of the thin slab on elastic foundation and space computing model of the truck are introduced. The results obtained from this slab computing model are compared with the results obtained from FEM analysis.

The first analytical solution of the moving load effect on structures is known from literature in connection with the disaster of the Chester Rail Bridge in England in the year 1847. Engineer R. Willis formulated the equation of motion describing the vibration of the elastic mass-less beam induced by moving the mass point with the constant velocity (Willis, 1849). The solution of the above equation of motion was carried out by G. G. Stokes by the development of deflections into the infinite series (Stokes, 1849). These two works started the stage of the analytical and numerical analyses of moving load effect on transport structures. The best known work concerning the moving loads effect on structures in the Czecho-Slovak Republic was published by (Frýba, 1972). Many researchers in the world pay attention especially to the solution of the problems of vehicle - road interaction. For example, the works of (Cebon, 1999) from the University of Cambridge are well-known as well as the works of (Kulakowski, 2009). The work of (Martinček, 1994) from the Slovak Academy of Sciences was especially dedicated to the dynamics of concrete pavements. The works of (Blab, 2004) dedicated to the solution of this problem are also known.

\section{Computational model of vehicle}

Generally, one, two or three dimensional computational model of vehicle can be adopted for the modelling of the dynamic effect of moving vehicles on the road structures. For the purpose of the task presented in this paper the space computational model of the truck TATRA has been adopted, Figure 1 . 


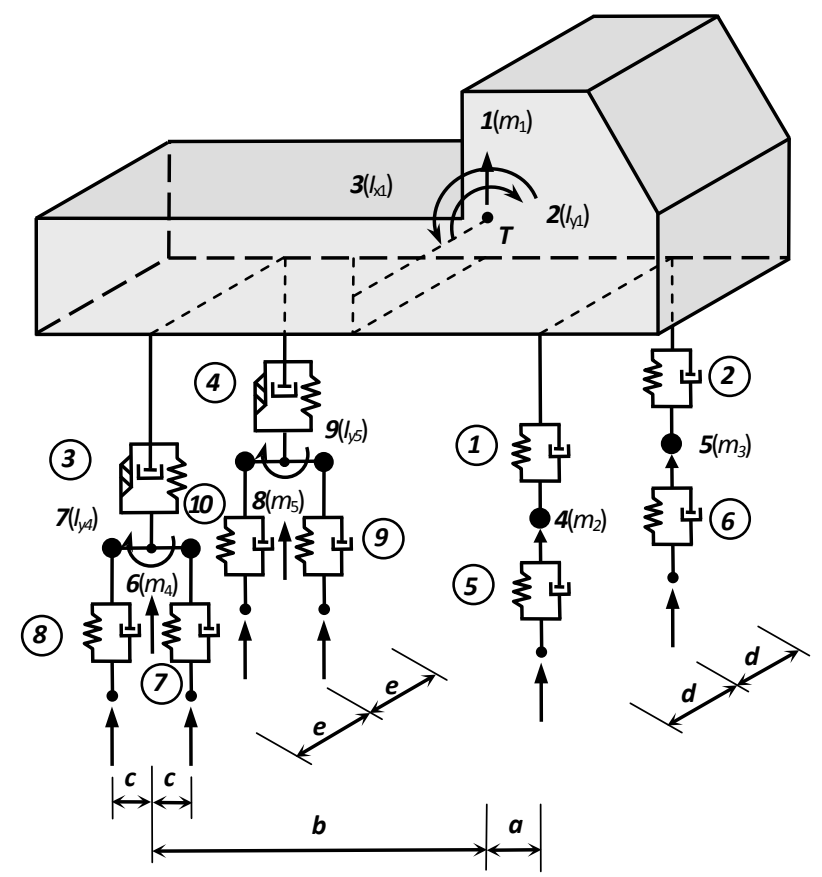

Figure 1. Space computational model of vehicle TATRA

The computational model of the truck has 15 degrees of freedom - 9 mass and 6 mass-less. The mass-less degrees of freedom correspond to the vertical movements of the contact points of the model with the surface of the roadway. The vibration of the mass objects of the model is described by the 9 functions of time $r_{i}(t)$, $(i=1,2,3,4,5,6,7,8,9)$. The unknown function $r_{i}(t)$ represent the displacement components of the points corresponding to the individual degrees of freedom of the vehicle. The mass-less degrees of freedom are associated with the tire forces $F_{j}(t),(j=5,6,7,8,9,10)$ acting at the contact points. It is the discrete computing model, so the equations of motion are in the form of ordinary differential equations and with respect to the used method of numerical solution they can be written in the form (Melcer et al., 2012)

$[m]\{\ddot{r}\}=\{F\}-[b]\{\dot{r}\}-[k]\{r\}=\{F\}-\left\{F_{d}\right\}-\left\{F_{r e}\right\}=\left\{F_{v}\right\}$,

where $[m],[b],[k]$ are the mass, damping and stiffness matrix and $\{F\},\left\{F_{d}\right\},\left\{F_{r e}\right\},\left\{F_{v}\right\}$ are the vectors of exciting, damping, restoring and resulting forces. Derivation with respect to the time $t$ is denoted by the dot over the symbol.

\section{Computational model of the road slab}

The computational model of the concrete pavement is based on the Kirchhoff theory of the thin slabs on elastic foundation (Frýba, 1972)

$$
D\left(\frac{\partial^{4} w}{\partial x^{4}}+2 \frac{\partial^{4} w}{\partial x^{2} \partial y^{2}}+\frac{\partial^{4} w}{\partial y^{4}}\right)+K w+\mu \frac{\partial^{2} w}{\partial t^{2}}+2 \mu \omega_{b} \frac{\partial w}{\partial t}=p(x, y, t) .
$$

The desired function $w(x, y, t)$ describing the slab vertical deflections will be expressed as the product of two functions

$w(x, y, t)=w_{0}(x, y) q(t)$.

The function $w_{0}(x, y)$ stands for the known function and it is dependent on the coordinates $x, y$ only and the function $q(t)$ stands for the unknown function and it is dependent on the time $t$. The function $q(t)$ has the meaning of generalized Lagrange coordinate. The assumption about the form of the function $w_{0}(x, y)$ has been introduced as, Figure 2 .

$$
w_{0}(x, y)=\frac{1}{4}\left(1-\cos \frac{2 \pi x}{l_{x}}\right)\left(1-\cos \frac{2 \pi y}{l_{y}}\right) \text {. }
$$


The meaning of the remaining symbols is as follows: $D$ slab stiffness $\left[\mathrm{N} \cdot \mathrm{m}^{2} / \mathrm{m}\right], K$ modulus of foundation $\left[\mathrm{N} / \mathrm{m}^{3}\right], \mu$ surface mass density $\left[\mathrm{kg} / \mathrm{m}^{2}\right], \omega_{b}$ circular frequency of damped vibration $[\mathrm{rad} / \mathrm{s}]$.
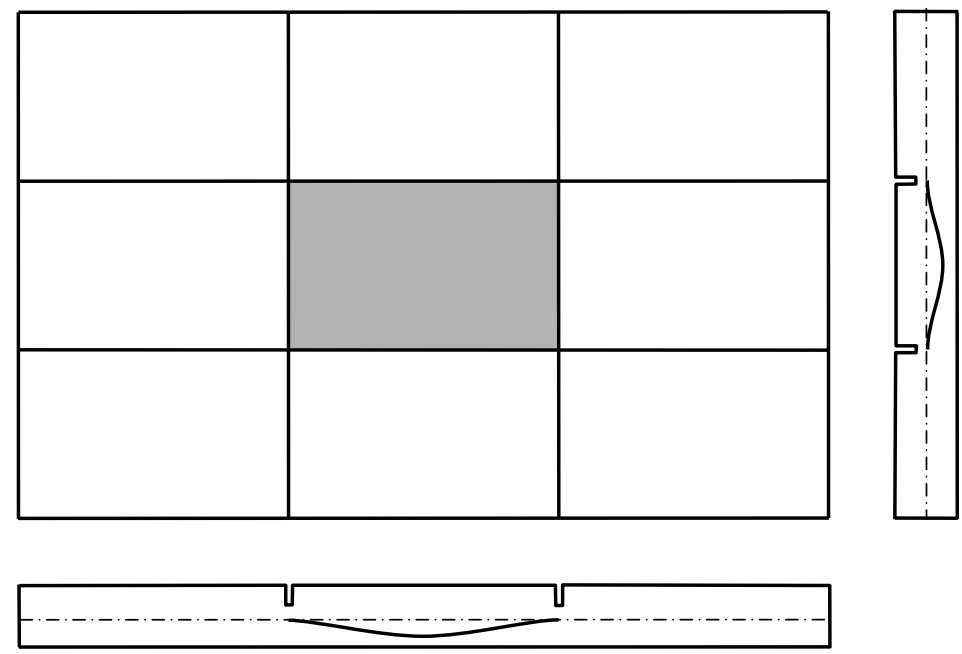

Figure 2. Assumption about the shape of the slab deflection area

$p(x, y, t)$ is the intensity of the dynamic load. In the case of moving vehicles the discrete load, due to the tire forces $F_{j}(t)$, must be transformed on a continuous load by the procedure proposed by Dirac (Frýba, 1972)

$$
\begin{aligned}
& p(x, y, t)=\sum_{j} F_{j}(t) \delta\left(x-x_{j}\right) \delta\left(y-y_{j}\right), \\
& p(x, y, t)=\sum_{j} \sum_{m=1}^{\infty} \sum_{n=1}^{\infty} p_{m n, j}(t) \frac{1}{4}\left(1-\cos \frac{m 2 \pi x}{l_{x}}\right)\left(1-\cos \frac{n 2 \pi y}{l_{y}}\right),
\end{aligned}
$$

where

$$
\begin{aligned}
p_{m n, j}(t) & =\frac{2}{l_{x}} \frac{2}{l_{y}} \int_{0}^{l_{x} \int_{0}} F_{j}(t) \delta\left(x-x_{j}\right) \delta\left(y-y_{j}\right) \frac{1}{4}\left(1-\cos \frac{m 2 \pi x}{l_{x}}\right)\left(1-\cos \frac{n 2 \pi y}{l_{y}}\right) \mathrm{d} x \mathrm{~d} y= \\
& =F_{j}(t) \frac{4}{l_{x} l_{y}} \frac{1}{4}\left(1-\cos \frac{m 2 \pi x_{j}}{l_{x}}\right)\left(1-\cos \frac{n 2 \pi y_{j}}{l_{y}}\right) .
\end{aligned}
$$

Then

$$
\begin{aligned}
p(x, y, t)=\sum_{j} \sum_{m=1}^{\infty} \sum_{n=1}^{\infty} F_{j}(t) \frac{1}{l_{x} l_{y}}( & \left.1-\cos \frac{m 2 \pi x_{j}}{l_{x}}\right)\left(1-\cos \frac{n 2 \pi y_{j}}{l_{y}}\right) . \\
& \cdot \frac{1}{4}\left(1-\cos \frac{m 2 \pi x}{l_{x}}\right)\left(1-\cos \frac{n 2 \pi y}{l_{y}}\right) .
\end{aligned}
$$

Regarding to the convergence of the series in equation (8) we can take into account the $1^{\text {st }}$ member of the series only. Then the equation (8) can be rewritten as

$$
p(x, y, t)=\sum_{j} F_{j}(t) \frac{1}{4 l_{x} l_{y}}\left(1-\cos \frac{2 \pi x_{j}}{l_{x}}\right)\left(1-\cos \frac{2 \pi y_{j}}{l_{y}}\right)\left(1-\cos \frac{2 \pi x}{l_{x}}\right)\left(1-\cos \frac{2 \pi y}{l_{y}}\right) .
$$

For the space truck computing model

$$
F_{j}(t)=-G_{j}+k_{j} d_{j}(t)+b_{j} \dot{d}_{j}(t), \quad(j=5,6,7,8,9,10),
$$


where $G_{j}$ is the gravity force of $j$-th axis, $k_{j}$ and $b_{j}$ stiffness and damping of the $j$-th tire and $d_{j}(t)$ is the tire deformation. Derivation with respect to the time $t$ is denoted by the dot over the symbol.

Substituting the assumption (3) and (4) into equation (2) the left side of the equation (2) will change into

$$
\begin{aligned}
& \ddot{q}(t)\left[\frac{1}{4} \mu\left(1-\cos \frac{2 \pi x}{l_{x}}\right)\left(1-\cos \frac{2 \pi y}{l_{y}}\right)\right]+\dot{q}(t)\left[\frac{1}{4} 2 \mu \omega_{b}\left(1-\cos \frac{2 \pi x}{l_{x}}\right)\left(1-\cos \frac{2 \pi y}{l_{y}}\right)\right]+ \\
& +q(t) \frac{1}{4}\left[-D\left(\frac{2 \pi}{l_{x}}\right)^{4} \cos \frac{2 \pi x}{l_{x}}\left(1-\cos \frac{2 \pi y}{l_{y}}\right)+2 D\left(\frac{2 \pi}{l_{x}}\right)^{2}\left(\frac{2 \pi}{l_{y}}\right)^{2} \cos \frac{2 \pi x}{l_{x}} \cos \frac{2 \pi y}{l_{y}}-\right. \\
& \left.-D\left(\frac{2 \pi}{l_{y}}\right)^{4}\left(1-\cos \frac{2 \pi x}{l_{x}}\right) \cos \frac{2 \pi y}{l_{y}}+K\left(1-\cos \frac{2 \pi x}{l_{x}}\right)\left(1-\cos \frac{2 \pi y}{l_{y}}\right)\right]=p(x, y, t) .
\end{aligned}
$$

When we study the deflections at one point of the slab only, for example, in the middle of the slab, than $x=l_{\mathrm{x}} / 2$ and $\mathrm{y}=l_{\mathrm{y}} / 2$ and the equation (2) comes by the definitive form

$$
\begin{array}{r}
\ddot{q}(t) \mu+\dot{q}(t) 2 \mu \omega_{b}+q(t) \frac{D}{2}\left[\left(\frac{2 \pi}{l_{x}}\right)^{4}+\left(\frac{2 \pi}{l_{x}}\right)^{2}\left(\frac{2 \pi}{l_{y}}\right)^{2}+\left(\frac{2 \pi}{l_{y}}\right)^{4}+2 \frac{K}{D}\right]= \\
=\sum_{j} F_{j}(t) \frac{1}{l_{x} l_{y}}\left(1-\cos \frac{2 \pi x_{j}}{l_{x}}\right)\left(1-\cos \frac{2 \pi y_{j}}{l_{y}}\right) .
\end{array}
$$

\section{Numerical analysis}

\subsection{Parameters of the slab computational model}

For the purpose of numerical analysis the following slab construction has been considered, Figure 3:

1. CS - concrete slab,

2. CA II - coating aggregate, quality class II,

3. SC I - soil cement, quality class I,

4. PC - protective coat, gravel sand,

5. SS - sub-soil,

$$
\begin{array}{rr}
h_{1}=240 \mathrm{~mm}, E_{1}=37500 \mathrm{MPa}, v_{1}=0.20 \\
h_{2}=40 \mathrm{~mm}, E_{2}=4500 \mathrm{MPa}, v_{2}=0.21 \\
h_{3}=200 \mathrm{~mm}, E_{3}=2000 \mathrm{MPa}, v_{3}=0.23 \\
h_{4}=250 \mathrm{~mm}, E_{4}=120 \mathrm{MPa}, v_{4}=0.35 \\
h_{5}=\infty \mathrm{mm}, E_{5}=\quad 30 \mathrm{MPa}, v_{5}=0.35
\end{array}
$$

\begin{tabular}{c}
\hline $\mathrm{CS} ; 240 \mathrm{~mm} ; E=37500 \mathrm{MPa} ; v=0.20$ \\
\hline $\mathrm{CA} \mathrm{II} \quad 40 \mathrm{~mm} ; E=4500 \mathrm{MPa} ; v=0.21$ \\
\hline $\mathrm{SC} \mathrm{I} ; 200 \mathrm{~mm} ; E=2000 \mathrm{MPa} ; v=0.23$ \\
\hline $\mathrm{PC} ; \quad 250 \mathrm{~mm} ; E=120 \mathrm{MPa} ; v=0.35$ \\
\hline $\mathrm{SS} ; \quad \infty \mathrm{mm} ; E=30 \mathrm{MPa} ; v=0.35$
\end{tabular}

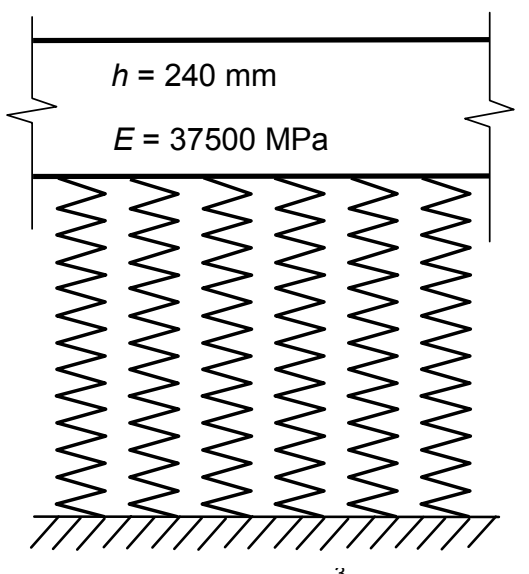

$\mathrm{K}=171.8 \mathrm{MN} / \mathrm{m}^{3}$ 
The $1^{\text {st }}$ layer of the computing model is the concrete slab of the thickness $h=240 \mathrm{~mm}$, the length $l_{\mathrm{x}}=6.8 \mathrm{~m}$, the width $l_{\mathrm{y}}=4.9 \mathrm{~m}$, modulus of elasticity $E=37500 \mathrm{MPa}$, Poisson ratio $v=0.20$. The surface mass density of the slab $\mu=\rho h=2500 \times 0.24=600.0 \mathrm{~kg} / \mathrm{m}$. The circular frequency of damped vibration is taken as $\omega_{b}=0.1 \mathrm{rad} / \mathrm{s}$. The layers $2-5$ are taken into calculation as Winkler elastic foundation. The modulus of compressibility $K=171.8 \mathrm{MN} / \mathrm{m}$ has been obtained as the result of the numerical loading test of the layered half-space, using the program LAYMED (Novorný et al., 1983).

The parameters of the truck computing model are as follows: $k_{1}=k_{2}=143716,5 \mathrm{~N} / \mathrm{m}, k_{3}=k_{4}=$ $=761256 \mathrm{~N} / \mathrm{m}, k_{5}=k_{6}=1275300 \mathrm{~N} / \mathrm{m}, k_{7}=k_{8}=k_{9}=k_{10}=2511360 \mathrm{~N} / \mathrm{m}, b_{1}=b_{2}=9614 \mathrm{~kg} / \mathrm{s}, b_{3}=b_{4}=$ $=130098.5 \mathrm{~kg} / \mathrm{s}, b_{5}=b_{6}=1373 \mathrm{~kg} / \mathrm{s}, b_{7}=b_{8}=b_{9}=b_{10}=2747 \mathrm{~kg} / \mathrm{s}, m_{1}=22950 \mathrm{~kg}, m_{2}=m_{3}=455 \mathrm{~kg}$, $m_{4}=m_{5}=1070 \mathrm{~kg}, I_{x 1}=22950 \mathrm{kgm}^{2}, I_{y 1}=62298 \mathrm{kgm}^{2}, I_{y 4}=I_{y 5}=466 \mathrm{kgm}^{2}, a=3.135 \mathrm{~m}, b=1.075 \mathrm{~m}$, $c=0.66 \mathrm{~m}, d=0.993 \mathrm{~m}, e=0.973 \mathrm{~m}$. The parameters of the truck computing model correspond to the truck TATRA 815.

\subsection{Influence of the velocity of the vehicle motion}

For the numerical solution of the mathematical apparatus, a computer program in the programming language MATLAB has been created. The program enables to calculate the time dependent change of all kinematical values (displacement, speed, acceleration) at mid-span of the slab and the time dependent change of contact forces under individual axles. The demonstrations of the form of the obtained results at the velocity of vehicle $V=65 \mathrm{~km} / \mathrm{h}$ are in the Figures $4,5,6,7$. When the vehicle moves along the axis of the slab symmetry the tire forces on the left and right side of vehicle are the same. Due to this reason the tire forces under the wheels on the right side of vehicle are presented.

The results of the solution are influenced by various parameters of the considered system (velocity of the vehicle motion, stiffness of subgrade, modulus of elasticity of the slab, thickness of the slab, road profile, etc.). The influence of the velocity of the vehicle motion has been analyzed in the interval of speeds $V=0-120 \mathrm{~km} / \mathrm{h}$ with the step of $5 \mathrm{~km} / \mathrm{h}$. The maximum of vertical displacements at the monitored point of the slab versus velocity of the vehicle motion are plotted in the Figure 8 . The position of the vehicle gravity centre at which the maximal slab deflection occurs is also shown in the Figure 8. The results are obtained for the smooth road surface.

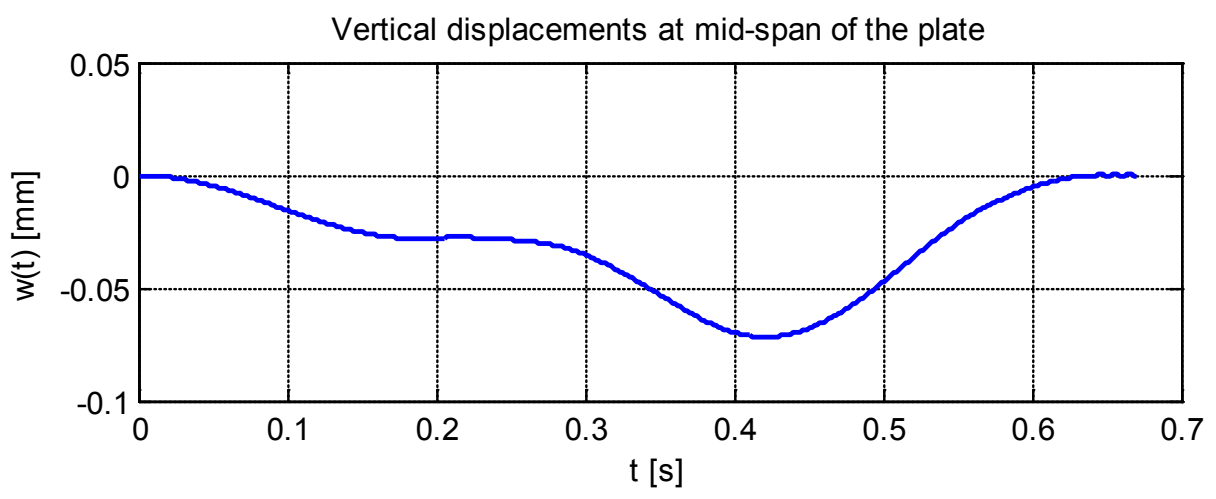

Figure 4. Vertical displacements at mid-span of the slab at the vehicle velocity $V=65 \mathrm{~km} / \mathrm{h}$

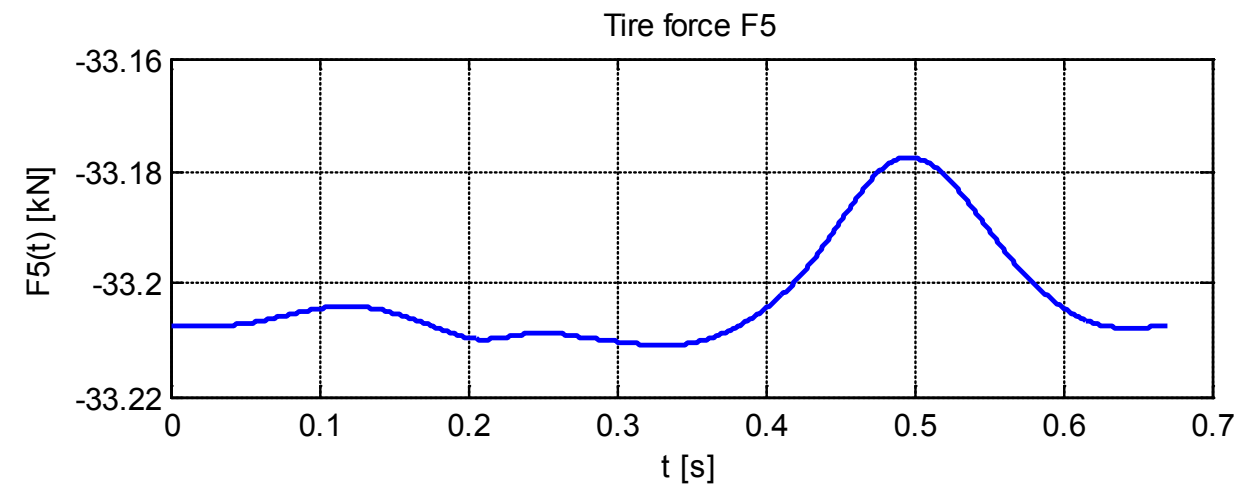

Figure 5. Tire force $F_{5}(t)$ under the right front wheel at the vehicle velocity $V=65 \mathrm{~km} / \mathrm{h}$ 


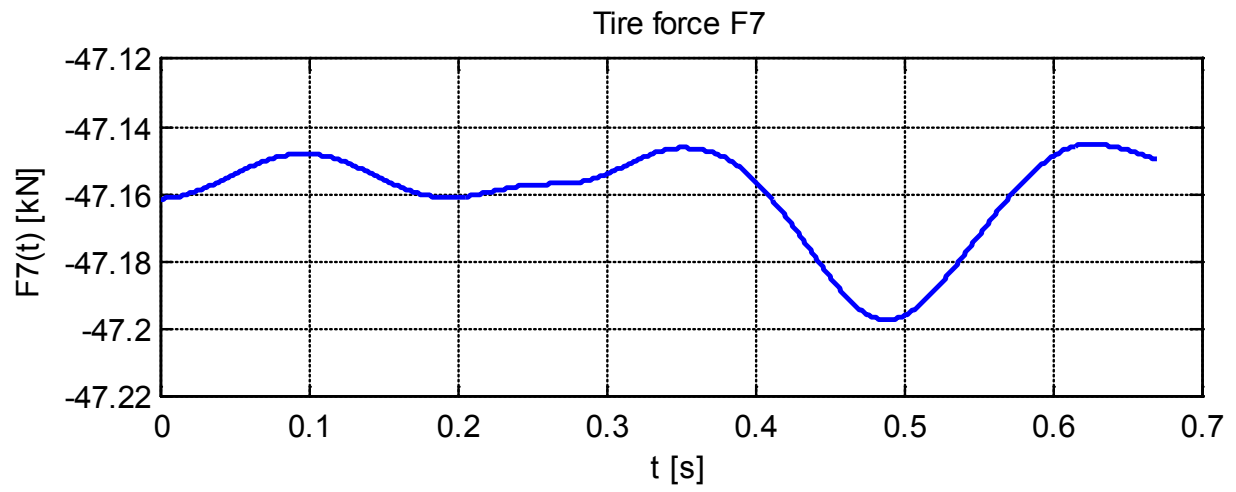

Figure 6. Tire force $F_{7}(t)$ under the right front wheel of the rear axle at the vehicle velocity $V=65 \mathrm{~km} / \mathrm{h}$

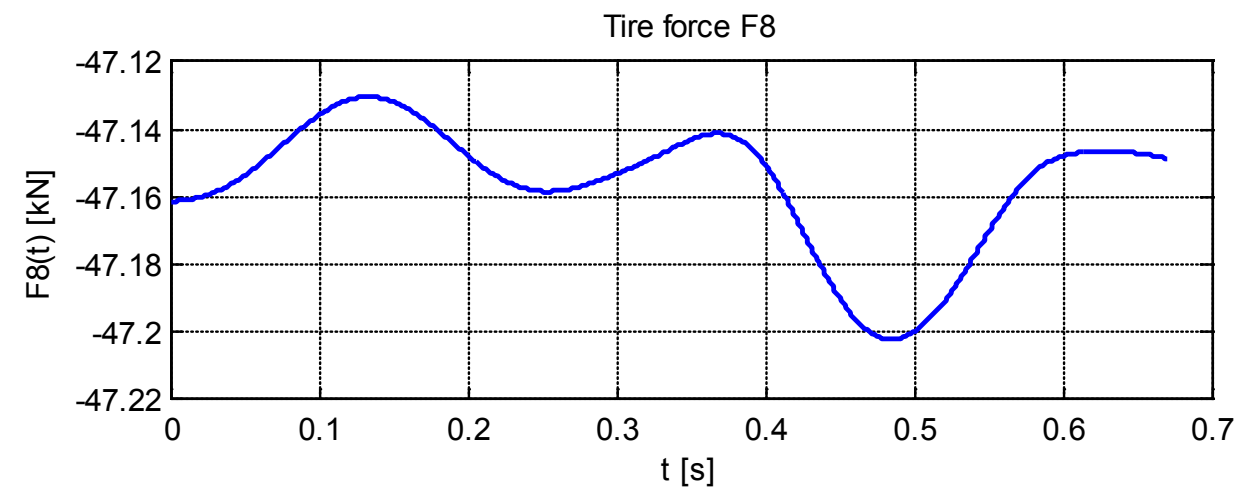

Figure 7. Tire force $F_{8}(t)$ under the right rear wheel of the rear axle at the vehicle velocity $V=65 \mathrm{~km} / \mathrm{h}$

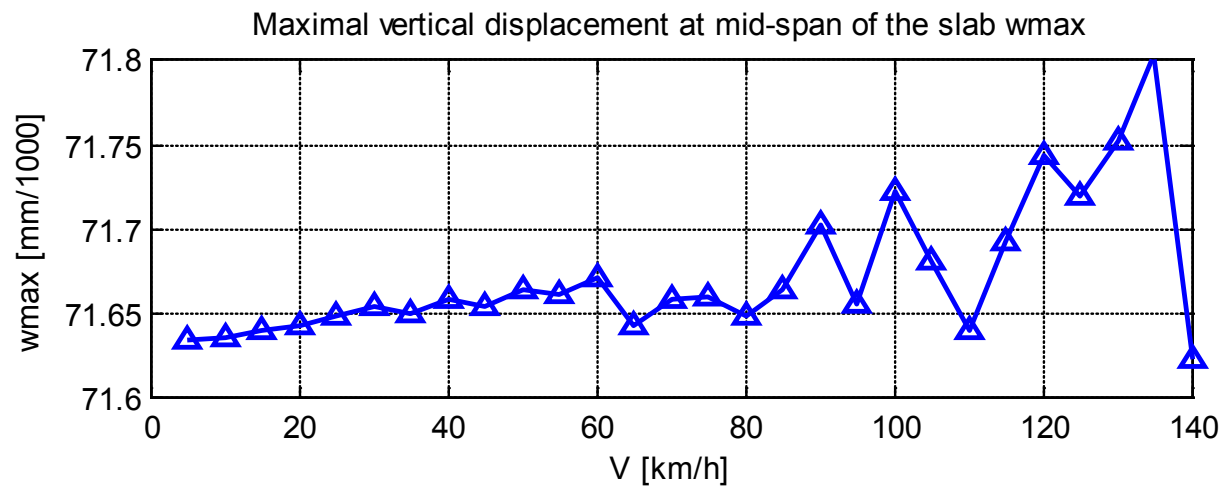

Positon of vehicle gravity centre

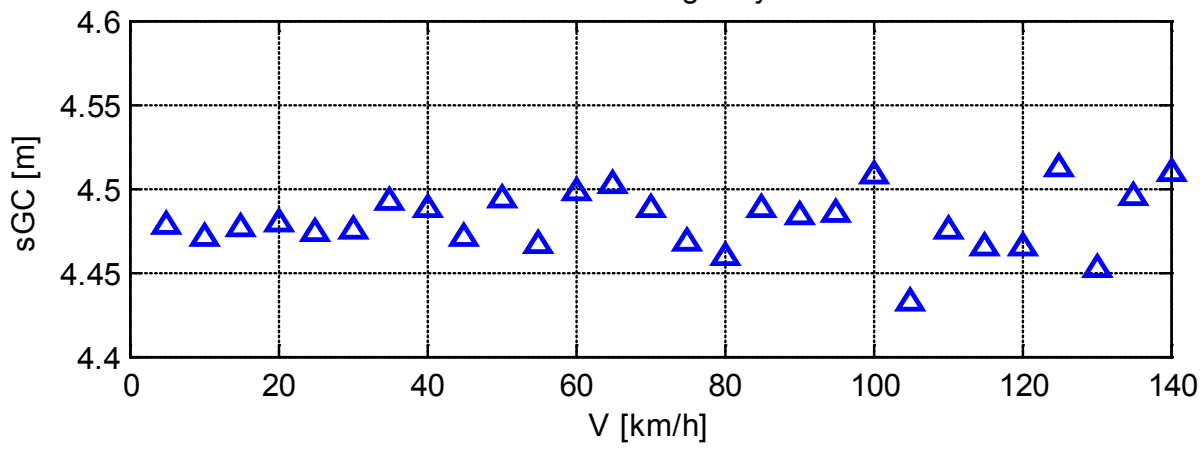

Figure 8. Maximal slab displacement and position of the vehicle gravity centre versus velocity $V$ 
The maximal slab displacement $w_{\max }=0.0718 \mathrm{~mm}$ corresponds to the velocity of the vehicle motion $V=135 \mathrm{~km} / \mathrm{h}$. The vehicle gravity center is situated $1.0948 \mathrm{~m}$ behind the middle of the slab at this moment.

\subsection{Influence of the subgrade stiffness}

The influence of the modulus of foundation $K$ was analyzed in the interval 50-200 MPa with the step of $25 \mathrm{MPa}$ and in the interval 200-500 MPa with the step of $50 \mathrm{MPa}$. The velocity of vehicle motion was $V=65 \mathrm{~km} / \mathrm{h}$. The maximum of vertical displacements at the monitored point of the slab versus the modulus of foundation are plotted in the Figure 9. The extremes (maximum, minimum) of the tire forces under the wheels on the right side of the vehicle versus the modulus of foundation are plotted in Figures $10,11,12$.

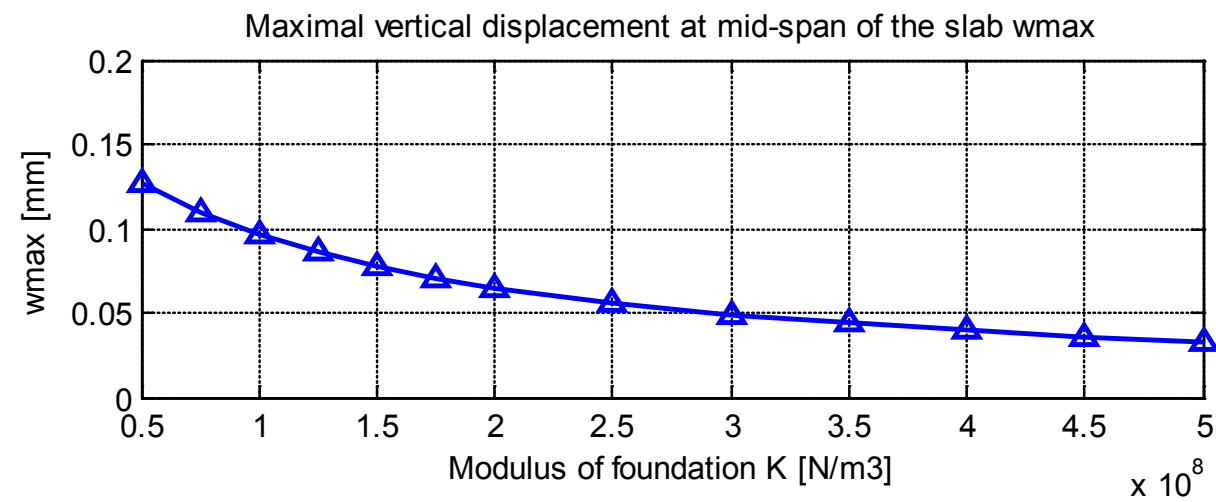

Figure 9. Maximal slab displacement and versus modulus of foundation $K$

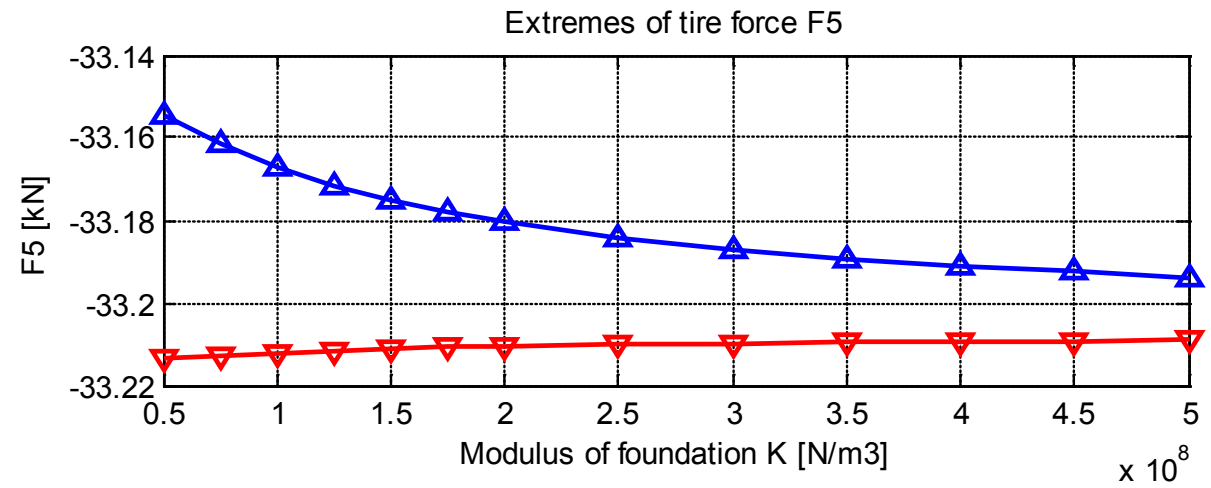

Figure 10. Extremes of tire force $F_{5}(t)$ versus modulus of foundation $K$

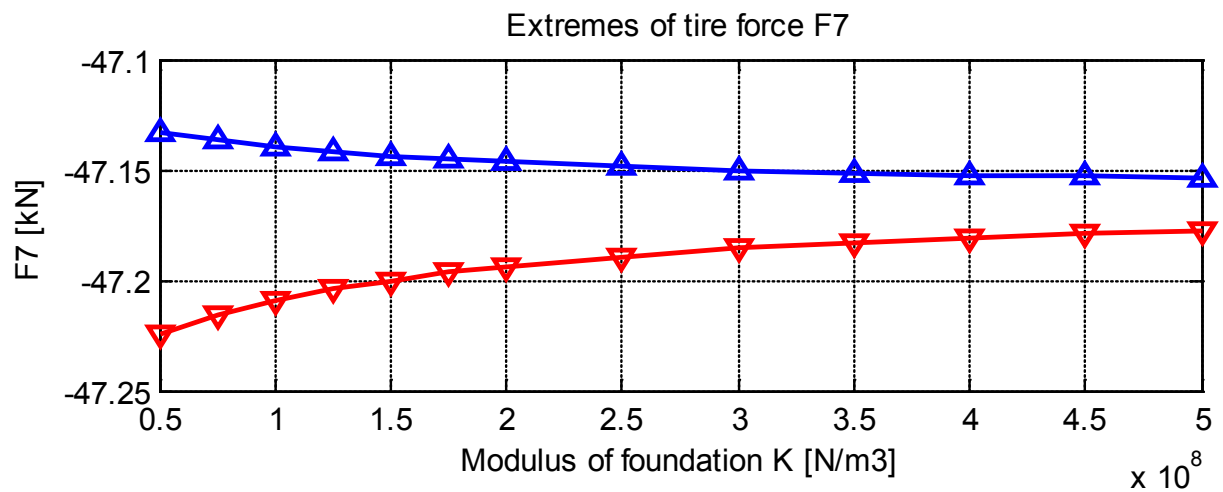

Figure 11. Extremes of tire force $F_{7}(t)$ versus modulus of foundation $K$ 


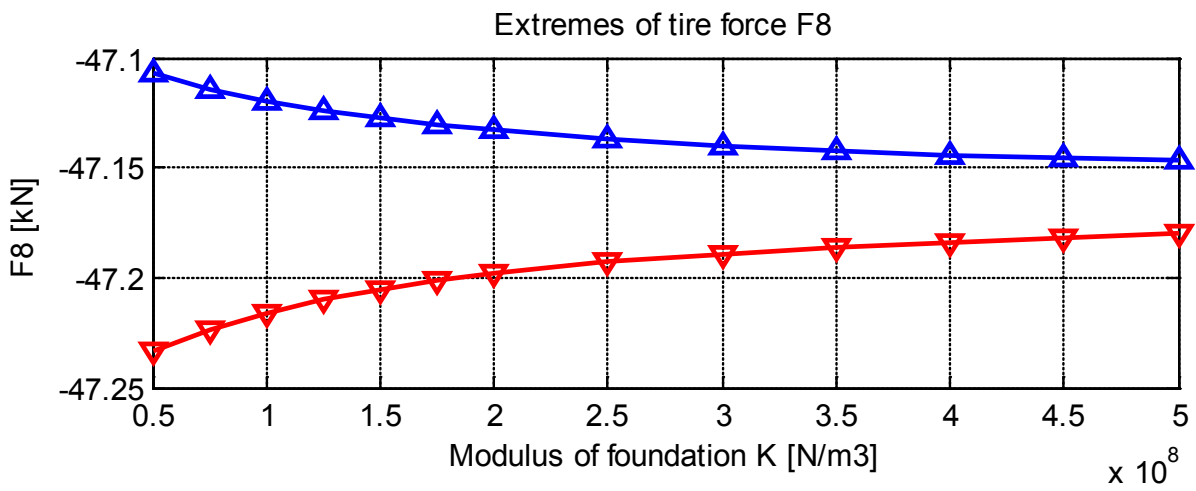

Figure 12. Extremes of tire force $F_{8}(t)$ versus modulus of foundation $K$

\subsection{Influence of the slab thickness}

The influence of the slab thickness $h$ was analyzed in the interval $5-40 \mathrm{~cm}$ with the step of $5 \mathrm{~cm}$. The velocity of the vehicle motion was $V=65 \mathrm{~km} / \mathrm{h}$. The maximum of vertical displacements at the monitored point of the slab versus the modulus of foundation are plotted in the Figure 13. The extremes (maximum, minimum) of tire forces under the wheels on the right side of the vehicle versus the modulus of foundation are plotted in Figures 14, 15, 16.

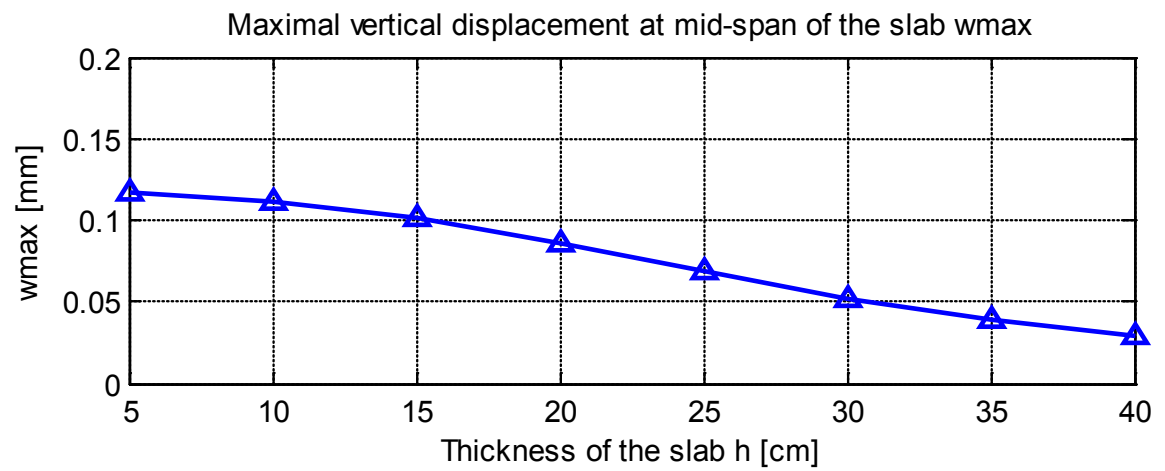

Figure 13. Maximal slab displacement and versus thickness of the slab $h$

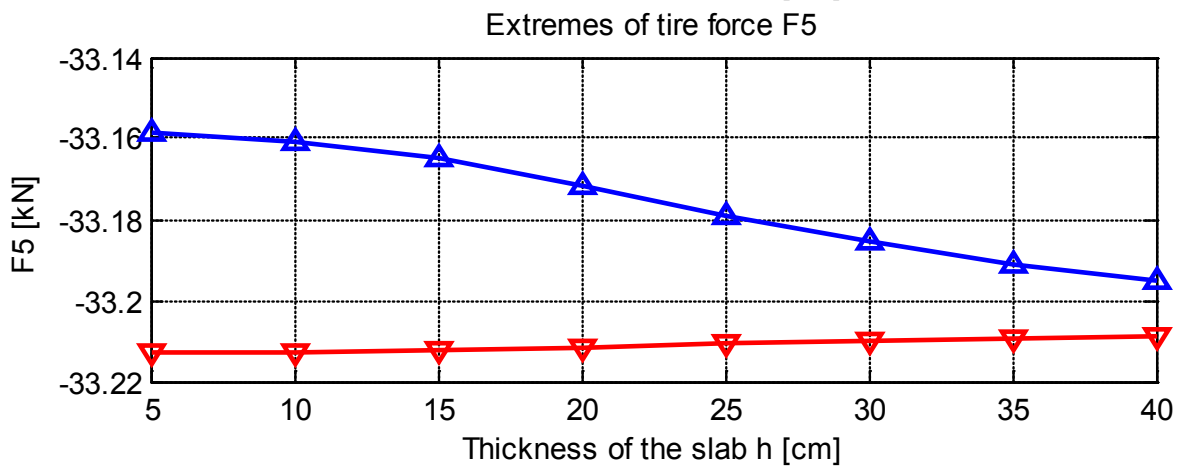

Figure 14. Extremes of tire force $F_{5}(t)$ versus the thickness of the slab $h$ 


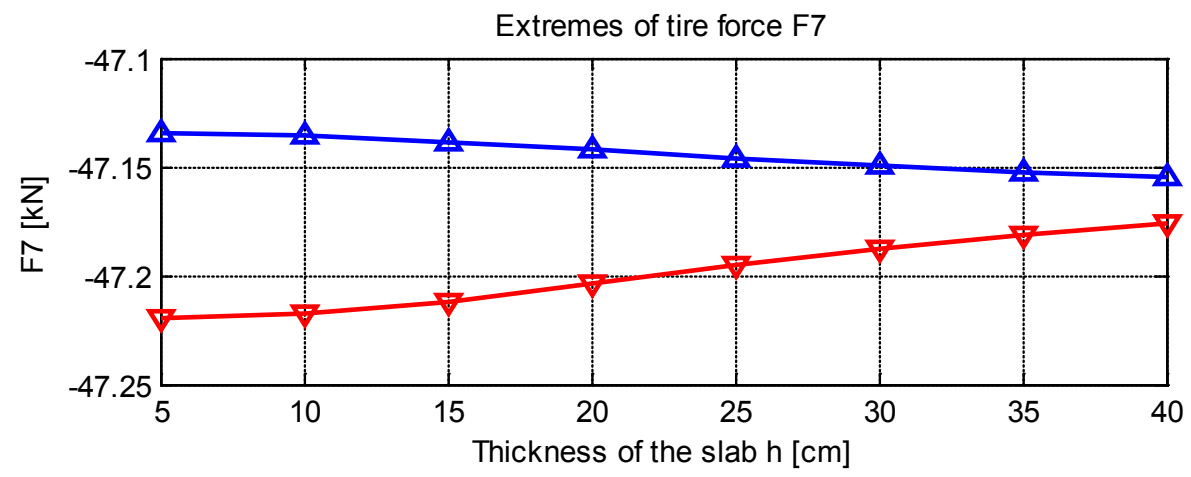

Figure 15. Extremes of tire force $F_{7}(t)$ versus the thickness of the slab $h$

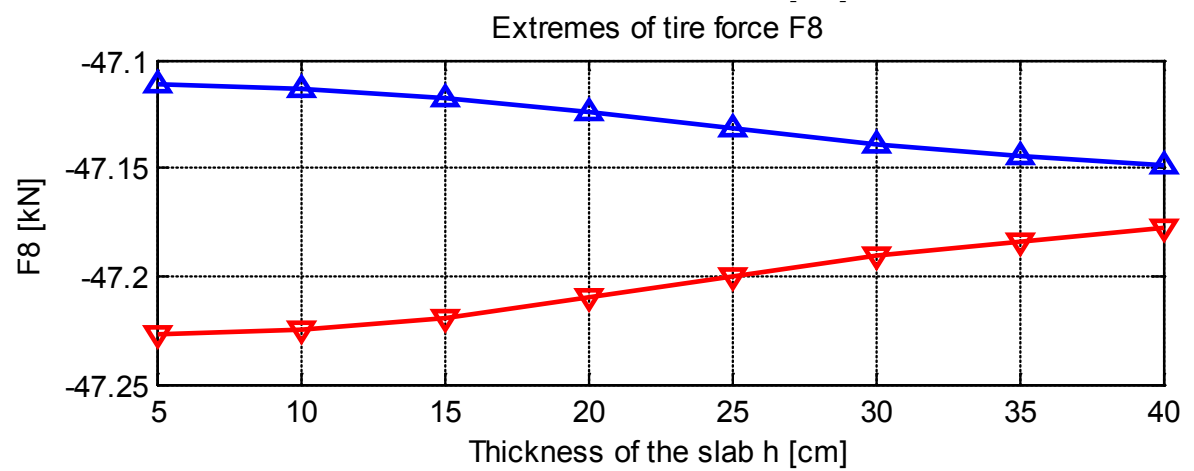

Figure 16. Extremes of tire force $F_{8}(t)$ versus the thickness of the slab $h$

It is possible now to carry out the general deduction. When the stiffness of the structure is increased for any reason, the vertical slab deflection is decreased and the range between the maximal and minimal value of the tire force is decreased.

\subsection{Influence of the road profile}

The above-mentioned results have been obtained for the smooth road profile. The real road profile has random character and it represents the dominant source of the kinematical excitation of the vehicle. Also the vehicle response has random character. The random road profile can be approximated by the Power Spectral Density (PSD) in the form of

$S(\Omega)=S(1) \times \Omega^{-k}$,

where $\Omega=2 \pi / L$ in $[\mathrm{rad} / \mathrm{m}]$ denotes the wavenumber and $S(1)=S\left(\Omega_{0}\right)$ in $\left[\mathrm{m}^{2} /(\mathrm{rad} / \mathrm{m})\right]$ describes the value of the PSD $S(\Omega)$ at reference wavenumber $\Omega_{0}=1 \mathrm{rad} / \mathrm{m}$. According to the international directive (ISO $8608,1995)$, typical road profiles can be grouped into classes from A to E. By setting the waviness to $k=2$, each class it is simply defined by its reference value $S(1)$. Class A with $S(1)=1 \times 10^{-6} \mathrm{~m}^{2} /(\mathrm{rad} / \mathrm{m})$, class $\mathrm{E} S(1)=256 \times 10^{-6} \mathrm{~m}^{2} /(\mathrm{rad} / \mathrm{m})$. In the next section the random road profile of a very good quality (class B, $S(1)=4 \times 10^{-6} \mathrm{~m}^{2} /(\mathrm{rad} / \mathrm{m})$ ) has been numerically generated by the equation (14)

$h(x)=\sum_{j=1}^{N} \sqrt{2 S\left(\Omega_{j}\right) \Delta \Omega} \cos \left(\Omega_{j} x+\varphi_{j}\right)$.

In the equation (14) the $\varphi_{j}$ is the uniformly distributed phase angle in the range between 0 and $2 \pi$. The same road profile has been generated in the left and right wheel trace. The generated road profile is shown in the Figure 17. 


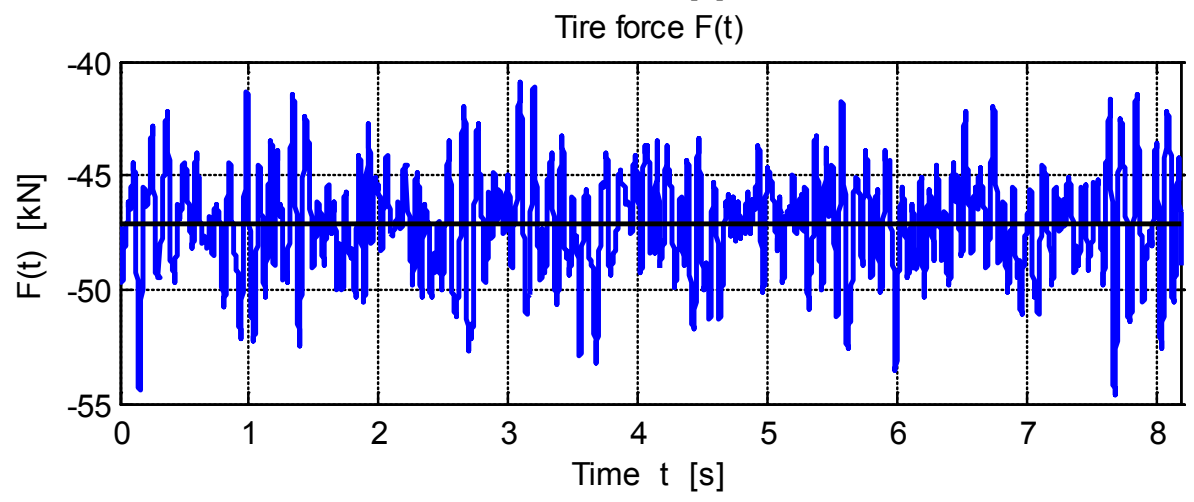

Figure 17. Random road profile, $S_{h}\left(\Omega_{0}\right)=4 \times 10^{-6} \mathrm{~m}^{2} /(\mathrm{rad} / \mathrm{m})$

The movement of the vehicle along the road profile with the velocity $V=36 \mathrm{~km} / \mathrm{h}$ has been numerically simulated. The results of the solution can be presented in the time or in the frequency domain. As an example, the tire force under the rear wheel of the rear axle $F_{8}(t)$ is presented in the Figure 18.

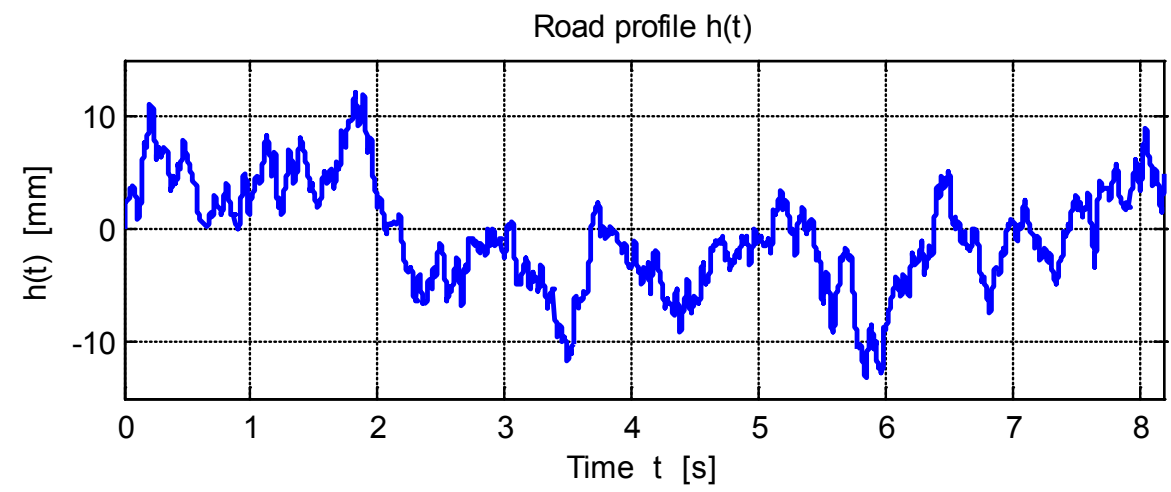

Figure 18. Tire force under the rear wheel of the rear axle $F_{8}(t)$

Similar results can be obtained for various road profiles and for various speeds of the vehicle motion. The decrease of the quality of the road profile results in the increasing values of the tire forces. In the Table 1 the ranges of the road profile $\Delta h=h_{\max }-h_{\min }$ and the corresponding ranges of the tire forces $\Delta F=\left|F_{\max }\right|-\left|F_{\min }\right|$ are introduced.

Table 1. Ranges of road profiles and tire forces for various road categories

\begin{tabular}{|l|l|l|l|}
\hline Road category & $S_{h}\left(\Omega_{0}\right)\left[\mathrm{m}^{2} /(\mathrm{rad} / \mathrm{m})\right]$ & $\Delta h=h_{\max }-h_{\min }[\mathrm{mm}]$ & $\Delta F=\left|F_{\max }\right|-\left|F_{\min }\right|[\mathrm{kN}]$ \\
\hline A & $1 \times 10^{-6}$ & 12.6190 & 6.8160 \\
\hline B & $4 \times 10^{-6}$ & 25.2380 & 13.6500 \\
\hline C & $16 \times 10^{-6}$ & 50.4760 & 27.3749 \\
\hline D & $64 \times 10^{-6}$ & 100.9519 & 54.5401 \\
\hline E & $256 \times 10^{-6}$ & 201.9038 & 76.9016 \\
\hline
\end{tabular}

At a certain road category, for example, at the category E, the tire forces are theoretically positive. In reality, the contact between the wheel and the road is lost, Figure 19. The wheel will bounce off the road and the impact will follow. It is a very bad situation not only for the pavement straining but also for the vehicle. So the quality of the road profile is the main factor within the process of the road maintenance. 
Tire force $F(t)$

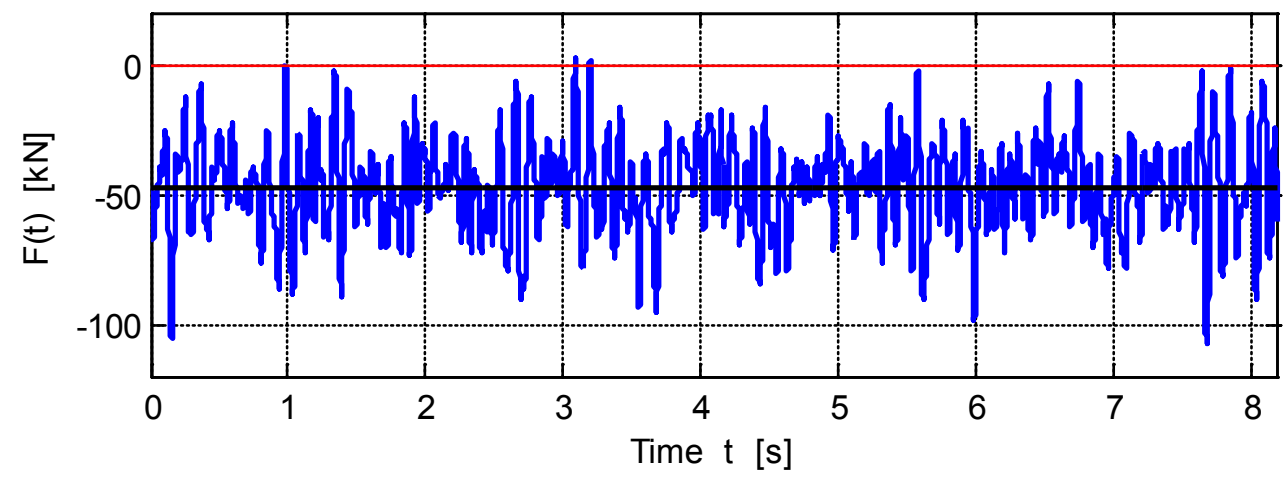

Figure 19. Time history of tire force $F_{8}(t)$ at the road category $E$

The solution can be carried out in the time domain, as shown above, or in the frequency domain. In the frequency domain, the frequency composition of vibration is interesting. It can be assessed, for example, through Power Spectral Density functions (PSD). The PSD function of the road profile informs us about the frequency composition of the road profile and the PSD of the tire force informs us about the frequency composition of the pavement load. The PSD of the road profile from Figure 17 is plotted in Figure 20 and the PSD of the dynamic component of the tire force from Figure 18 is plotted in Figure 21. As we can see, in the frequency composition of the road profile the low frequencies dominate. In the frequency composition of the tire forces the frequencies in the interval from 6 to $12 \mathrm{~Hz}$ dominate. It relates to the natural frequencies of the vehicle.

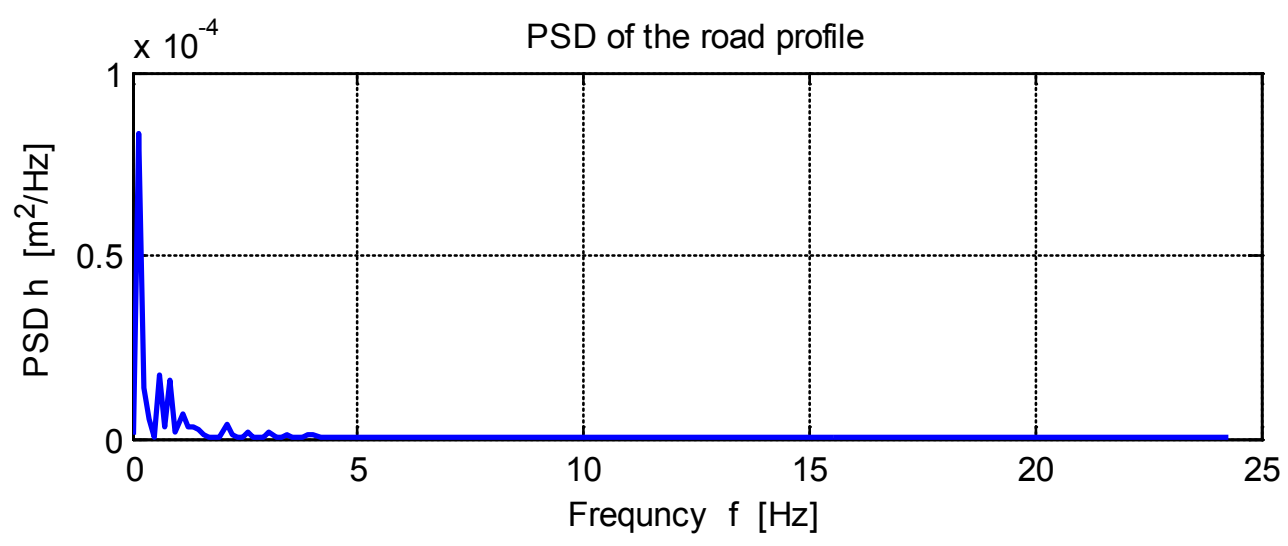

Figure 20. PSD of the road profile

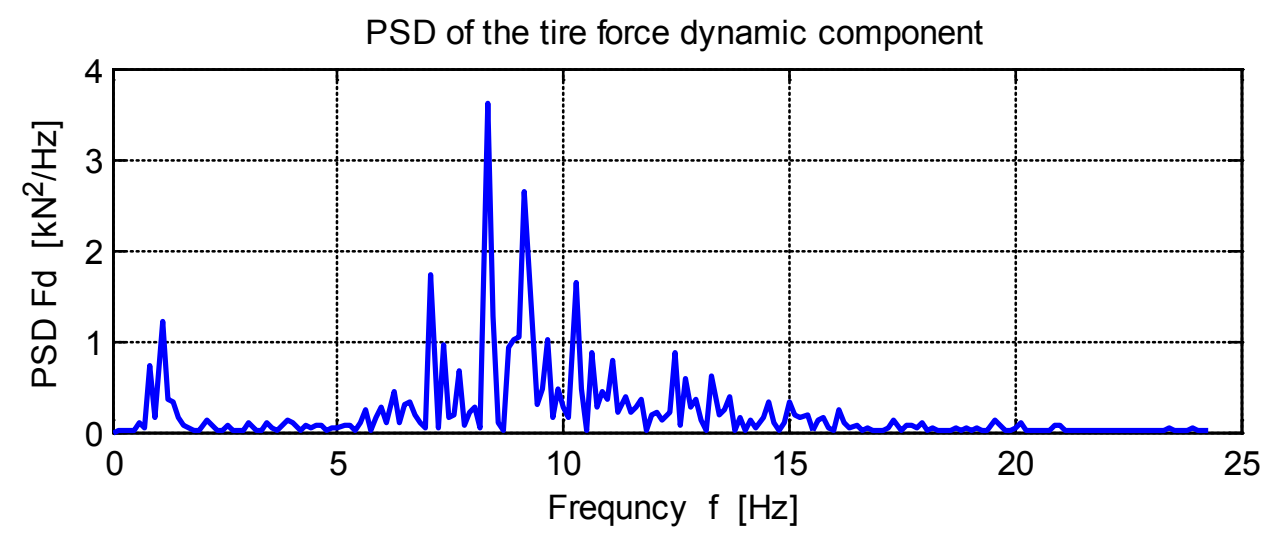

Figure 21. PSD of the dynamic component of tire force $F_{8}(t)$ 


\section{Comparison of the slab and FEM computing models}

The finite element computing model was created for such pavement as the model of the slab on the layer half space. The solved area is $20.4 \times 14.7 \mathrm{~m}$ large. It is divided into $48 \times 30=1440$ finite elements. The dividing of the structure into finite elements and the state of deformation at a certain time moment are shown in Figure 22.

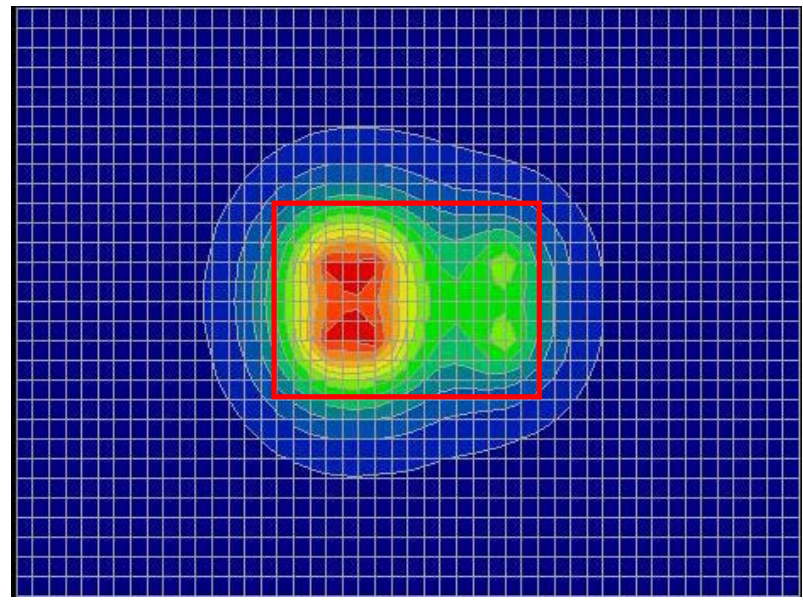

Figure 22. FE model of the slab on the layer half space

With respect to the fact that classical slab computing model on Winkler foundation gives the results in one point only, in the middle of the slab, the deflections in the middle of the slab are compared with the deflections in the middle of the FE modeled area. The comparison of the results in a graphic form is in Fig. 23. The green colour represents the results from the FE model of the slab on the layered foundation (FEM) and the blue colour shows the results from the classical slab model on Winkler foundation (CSM). The plotted curves have two local extremes. In the area of the $1^{\text {st }}$ local extreme the difference of monitored values is $\Delta w_{1}=0.00623 \mathrm{~mm}$ and in the area of the $2^{\text {nd }}$ local extreme the difference of monitored values is $\Delta w_{2}=0.00017 \mathrm{~mm}$.

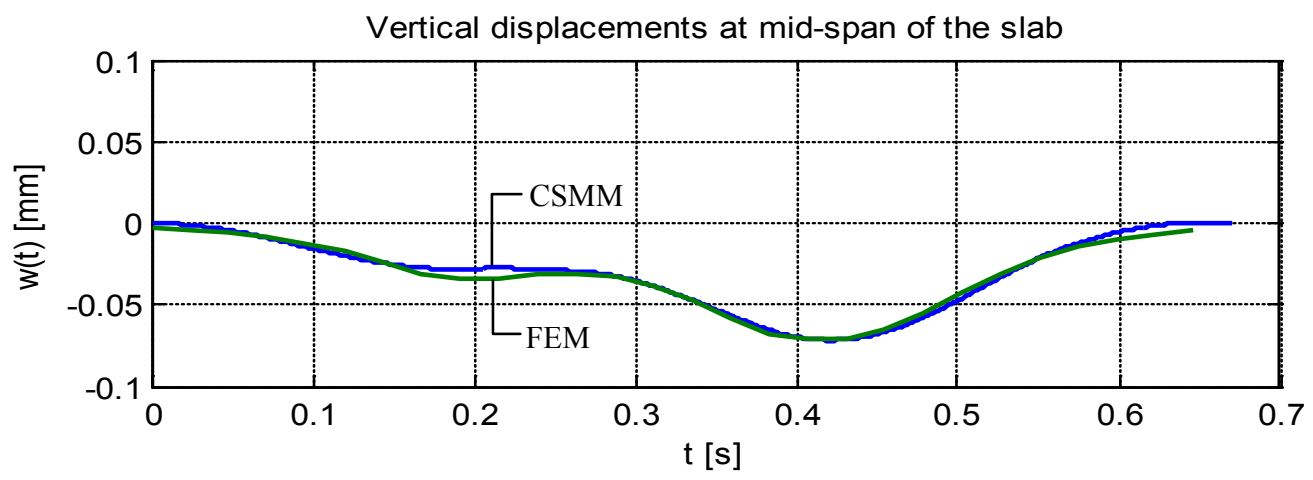

Figure 23. Comparison of the results of FEM and CSM

\section{Conclusion}

Vehicle - road dynamic interaction is a current engineering problem which can be analysed in a numerical or experimental way. The integral part of the numerical solution is the creation of computing models. The computing models of vehicles are usually created as discrete computing models described by the system of ordinary differential equations. For modelling the pavement structure, the finite element method is commonly used. But there are also other methods of solution. For simulation of the dynamic effect of moving vehicles, concrete pavements can be modelled as the slab on the elastic foundation. 
When the stress-strain characteristics are analysed at one point only, for example, in the middle of the slab, the assumption about the shape of the slab deflection area can be adopted. On the basis of this assumption, a partial differential equation of the slab can be replaced by an ordinary differential equation. Such computing model enables us to analyze all kinematic values (displacement, velocity, acceleration) of the vehicle as well as the kinematic values at the monitored point of the slab and tire forces. Various parameters come into account. In this paper, there have been analyzed the influence of the velocity of the vehicle motion and the influence of stiffness characteristics (modulus of foundation, slab thickness). The deflections of the slab and the extremes of contact forces grow with the velocity of the vehicle motion. The influence of stiffness characteristics has the opposite tendency in comparison with the influence of the velocity of the vehicle motion. The deflections of the slab and the extremes of contact forces decline with the growing values of stiffness characteristics. When the slab has good surface without evident unevenness the influence of all parameters on the kinematic and force quantities is very small. A real road profile is usually not ideal. It has a stochastic character and represents the dominant source of the kinematic excitation of the vehicle. Deterioration of the road profile leads to the increase of pavement straining. The analysis in the time domain can be extended to the analysis in the frequency domain which informs us about the frequency composition of all monitored quantities.

\section{Acknowledgements}

The research has been supported by the Grant National Agency VEGA. Project No. G 1/0259/12.

\section{References}

1. Willis, R. (1849) Appendix, Report of the Commissioners Appointed to Inquire into the Application of Iron to Railway Structures. Stationary Office, London.

2. Stokes, G.G. (1849) Discussion of a Differential Equation Relating to the Breaking of Railway Bridges. Transactions Cambridge Philosophic Society, 8, p. 707.

3. Frýba, L. (1972) Vibration of Solids and Structures under Moving Loads. ACADEMIA, Praha, Noordhoff International Publishing, Groningen.

4. Cebon, D. (1999) Handbook of Vehicle - Road Interaction. Swets\&Zeitlinger Publishers, Lisse, Netherlands.

5. Kulakowski, B. T., Gardner, J. F., Lowen, S. J. (2009) Dynamic Modelling and Control of Engineering Systems. The $3^{\text {rd }}$ edition, Cambridge University Press, New York.

6. Martinček, G. (1994) Dynamics of Pavement Structures. E \& FN Spon and Ister Science Press, London/Bratislava.

7. Blab, R. (2004) Designing Concrete Pavements for High Traffic Loads: The A23 Urban Motorway in Vienna. In: Betontag 2004, Austria Center Vienna, Marth 18-19,2004, pp. 32-38.

8. Novotny, B., Hanuska, A. (1983) Theory of layered half-space (in Slovak), VEDA, SAV, Bratislava.

9. ISO 8608 (1995) Mechanical vibration - road surface profiles - reporting of measured data. International standard.

10. Melcer, J. and Lajčáková, G. (2012) Numerical simulation of vehicle motion along road structure. Roczniki inzynierii budowlanej, zeszyt 12/2012, p.37-42, ISSN 1505-8425. 